\title{
Review \\ Hypoxia and oxidative stress in breast cancer Hypoxia signalling pathways
}

\author{
Christopher W Pugh, Jonathan Gleadle and Patrick H Maxwell
}

Henry Wellcome Building of Genomic Medicine, University of Oxford, Oxford, UK

Correspondence: C W Pugh, Henry Wellcome Building of Genomic Medicine, Roosevelt Drive, Headington, Oxford, OX3 7BN, UK. E-mail: cwpugh@enterprise.molbiol.ox.ac.uk

Received: 4 May 2001

Revisions requested: 10 May 2001

Revisions received: 18 May 2001

Accepted: 31 May 2001

Published: 16 July 2001
Breast Cancer Res 2001, 3:313-317

(C) 2001 BioMed Central Ltd

(Print ISSN 1465-5411; Online ISSN 1465-542X)

\begin{abstract}
Hypoxia-inducible factor-1 (HIF), which is centrally involved in physiological oxygen homeostasis, is also activated in the majority of tumours. Activation of HIF can occur through genetic mechanisms or as a result of hypoxia within the tumour microenvironment. In some cases HIF activation appears to be intimately linked to the proliferative stimulus itself. HIF affects patterns of gene expression and tumour growth, although precise effects vary between tumour types. Modulation of HIF activity, if correctly applied, may be therapeutically beneficial in tumour therapy.
\end{abstract}

Keywords: angiogenesis, hypoxia-inducible factor, oxygen, tumour, von Hippel-Lindau

\section{Introduction}

Oxygen homeostasis is of critical importance for all mammalian cells, because too much oxygen results in toxicity and too little impairs metabolism. Maintenance of oxygen levels within tight limits is essential throughout life, but is particularly important during periods of rapid cellular proliferation, both in normal development and neoplasia. Control of oxygen levels in the tissues of an animal occurs through a combination of gene regulatory, biochemical and physiological mechanisms. The present review focuses on the considerable advances that have been made during the past decade in our understanding of the gene regulatory processes involved.

An important insight into the molecular basis of oxygen homeostasis arose through studies on the control of erythropoietin expression. The hormone erythropoietin is central to the feedback loop that regulates tissue oxygenation. By increasing red cell production in response to tissue hypoxia, erythropoietin increases tissue oxygen delivery, thereby mitigating the original stimulus. Interestingly, erythropoietin levels can also be increased by iron chelation.
Erythropoietin levels are principally controlled by transcriptional regulation of erythropoietin gene expression by a hypoxically regulated enhancer that is located $3^{\prime}$ to the gene. It was initially considered likely that regulation of erythropoietin gene transcription by hypoxia represents a special case. However, early studies following the identification of the erythropoietin hypoxically regulated enhancer demonstrated that it was a paradigm for a central mechanism of oxygen-regulated gene expression operative in most, if not all, cell types [1]. Subsequently, HIF was identified as the novel transcription factor that operates this enhancer; it too was found to be widely expressed and operative $[2,3]$. Although the activity of many transcription factors, including fos, jun and p53, is affected by tissue oxygenation, thereby influencing gene regulation, it has become increasingly apparent that HIF is the dominant transcription factor that affects gene expression by oxygen levels.

\section{Hypoxia-inducible factor-1, and the hypoxia inducible factor-1 system}

HIF is a heterodimer of $\alpha$ and $\beta$ subunits, each of which exist as gene families, and all of which are members of the

$\mathrm{HIF}=$ hypoxia-inducible factor-1; VHL = von Hippel-Lindau. 
PAS superfamily of transcription factors [3]. The $\beta$ subunits (also known as aryl hydrocarbon receptor nuclear translocators) are constitutively nuclear proteins that also have roles in transcriptional responses to xenobiotic agents. In contrast, the $\alpha$ subunits have to date only been shown to take part in gene regulatory responses to hypoxia and iron chelation.

Following the recognition that the erythropoietin enhancer (to which HIF binds) was widely operative and that HIF itself was widely expressed, it was logical to explore the activity of this mechanism in the hypoxic regulation of genes other than the erythropoietin gene. Initial studies focused on genes with known functions that were expected to be regulated by oxygen levels. Those studies implicated HIF in the regulation of such diverse processes as glycolysis, glucose transport and angiogenesis (for review [4]). A striking concordance between patterns of gene expression that have classically been associated with cancer and the range of genes induced by HIF activation in cultured cells was noted [5]. More recently, unprejudiced approaches such as differential display polymerase chain reaction, screening of gene arrays and studies in HIF-deficient mutant cells [6,7] have broadened the number of processes that are known to be regulated by this complex. Interestingly, HIF target genes with antiproliferative and proapoptotic actions have thus been identified. Given the combinatorial nature of gene regulation, it is clear that the genes that are actually controlled by HIF may vary from cell type to cell type, as indeed is exemplified by the tissue specificity of erythropoietin expression.

\section{Regulation of the hypoxia inducible factor-1 complex occurs at many levels}

Initial reports suggested that HIF subunit mRNA levels were regulated by hypoxia. In cell lines such effects are modest and insignificant compared with post-translational mechanisms, but the situation may be different in some primary cells.

When oxygen tension is lowered, HIF $\alpha$ subunits are stabilized, translocate to the nucleus and dimerize with a $\beta$ subunit. The HIF complex binds hypoxia response elements, recruits the coactivator CREB-binding protein/P300 via the carboxyl-terminus of the $\alpha$ subunit [8] and activates transcription of a range of genes. Although many steps in this pathway are sensitive to variation in oxygen levels, the dominant mode of regulation is through oxygen-dependent destruction of HIF $\alpha$ subunits by the ubiquitin-proteasome pathway $[9,10]$. This destruction is mediated by a ubiquitin E3 ligase complex, in which the von Hippel-Lindau (VHL) tumour suppressor protein recognizes and binds oxygendependent destruction domain(s) in the HIF $\alpha$ subunits $[11,12]$. This recognition of HIF $\alpha$ subunits in normoxia has recently been shown $[13,14]$ to be conditional on iron-dependent and oxoglutarate-dependent enzymatic post-translational hydroxylation of critical prolyl residues. It is known that this family of dioxygenases use superoxide as a catalytic intermediate, and it is possible that redox agents that are known to influence HIF activation act by modulating enzymatic activity.

As yet it remains unclear how many other aspects of gene regulation can be explained by such enzymatic modification. In the context of hypoxia it could underlie the concordant regulation of all activating functions of HIF, including coactivator recruitment by the carboxyl-terminus and nuclear localization. It might also be responsible for influences on mRNA stability, which appear to underlie other forms of gene regulation by hypoxia. Furthermore, the discovery of this mechanism may have general implications for our understanding of the function of PEST domains, which are known to be associated with protein instability.

The direct pathway outlined above operates in a complex intracellular environment, and increasing evidence exists for direct or indirect sensitivity to other influences. For example, there are reports of activation of HIF in response to inactivation of a number of different tumour suppressor genes, in response to activation of several different oncogenes and in response to activation of diverse growth factor pathways (see below).

\section{Hypoxia inducible factor-1 activation in cancer} It is now recognized that HIF activation in cancer can occur both in response to microenvironmental tumour hypoxia and as a result of genetic mechanisms.

Use of experimental tumours with and without an intact HIF system [15] showed the HIF-dependent regional expression of HIF regulated endogenous genes, particularly in perinecrotic areas. Studies of xenografts that express a stably integrated, hypoxically regulated, enhancer dependent reporter gene [16] also showed regional activation. Importantly, the use of comet assays provided further evidence that these regions were indeed hypoxic. Immunostaining for the $\alpha$ subunit can be used to identify the extent of HIF activation in natural tumours, because HIF $\alpha$ stabilization is necessary for formation of active HIF. Although there may be threshold effects and the short half-life of this molecule requires immense care with fixation, HIF $\alpha$ chains are observed within regions in over half of all solid malignant tumours, most commonly in perinecrotic areas $[17,18]$.

Although rapidly proliferating cells will outstrip the available oxygen supply, with consequent hypoxia and HIF activation, there is evidence for more direct links between proliferation and amplification of the HIF response. Thus, activation of several oncogenes (Ha-ras, myc and src), loss of tumour suppressor functions ( $\mathrm{p53}$, PTEN) and exposure to different growth factors (insulin, insulin-like growth factor-1 and 
-2 , angiotensin II) have been reported to increase HIF activity in normoxia and hypoxia, with a preserved hypoxic response $[19,20]$. The proposed mechanisms of amplification differ. Expression of $\mathrm{v}$-src increases HIF-1 $\alpha$ protein and target gene activation, an effect that appears to involve an increase in HIF-1 $\alpha$ mRNA [21]. Effects that are modulated via AKT (protein kinase B) and phosphatidylinositol 3 kinase are believed to underlie the actions of PTEN $[22,23]$ and Ha-ras [24,25], respectively, although these actions may not be direct. p42/p44 Mitogen-activated protein kinase has been implicated in HIF $\alpha$ phosphorylation, and activation of mitogen-activated protein kinase promotes transcriptional activation by HIF [26]. Wild-type p53 has been reported to promote MDM2-mediated ubiquitylation and degradation of HIF-1 $\alpha$ in at least some circumstances [27]. In contrast c-myc acts directly on the HIF responsive enhancer elements [28].

In VHL syndrome a mutant VHL allele is inherited. Tumours in which the second VHL allele is defective develop in a limited range of tissues. Cells from these tumours show constitutive HIF activation as a result of failure of normoxic recognition, and thus ubiquitylation, by the VHL E3 ligase complex. Similarly, spontaneous renal carcinoma cell lines that lack the VHL tumour suppressor protein also show constitutive activation of the HIF system. Experimental reintroduction of a wild-type $\mathrm{VHL}$ gene into these cells results in reduced tumour growth. Thus, in at least some cell types constitutive activation of the HIF system is not only tolerated, but confers advantages for tumour cell growth. Conversely, as described above, it is clear that the HIF pathway remains sensitive to oxygen in a very wide range of cancer cells. Because HIF activation offers potential advantages to proliferating cells, this suggests that balancing pressures prevent maximal HIF activation. The known ability of HIF to activate antiproliferative and proapoptotic genes provides a plausible selective pressure against constitutive HIF activation in many tumours.

Variable effects have been demonstrated in experimental tumours. In studies that compared mouse hepatoma cells with wild-type or defective HIF pathways, as a result of HIF-1 $\beta$ deficiency, the mutant cells showed both reduced angiogenesis and reduced tumour growth [15]. Studies in HIF-1 $\alpha$-deficient mouse embryonic stem cells have in one case yielded similar results [29], but other studies showed enhanced growth in the deficient cells that were resistant to hypoxia-induced apoptosis [30]. In another study [31] tumours derived from HIF-1 $\alpha$-deficient fibroblasts grew at a slower rate than their wild-type counterparts, despite similar angiogenic development.

\section{Hypoxia, hypoxia inducible factor-1 and tumour prognosis}

The extent of tumour hypoxia is known to correlate with poor prognosis [32]. Hypoxia appears to be a direct marker of tumour aggressiveness, but ischaemic areas are protected against standard therapies, receiving a lower dose of systemically administered chemotherapeutic agents and being more radioresistant as a result of reduced generation of oxygen radicals.

Knowledge of the relationship between HIF activity and tumour prognosis is currently in its infancy. Immunodetection of HIF $\alpha$ chains now provides a route to quantify and localize HIF activation. Caution is required, however, because the rapid modulation of HIF $\alpha$ protein levels in response to changes in tissue oxygenation means that differences in the handling of clinical specimens between the time of surgical cross-clamping and fixation can result in spurious upregulation or downregulation of the amount detected. Despite these concerns, in one study of breast cancer [33] positive staining for HIF-1 $\alpha$ appeared to be associated with more aggressive tumours. However, in a study of non-small-cell lung cancers [34] survival was better in patients with HIF-positive tumours than in those with HIF-negative tumours. It is not yet clear whether these observations relate to fundamental differences in the role of HIF in the biology of these tumour types, or whether there are other explanations for them.

\section{Opportunities for therapeutic intervention}

The observed upregulation of HIF in many cancers, the role of HIF in upregulation of angiogenic growth factors, and the role of angiogenic growth factors in tumour growth suggests that downregulating the HIF system could potentially be beneficial in tumour therapy. The xenograft experiments described above established that, in some circumstances, blocking the HIF response can have beneficial effects on tumour angiogenesis and growth $[15,29]$. Manoeuvres such as complete suppression of HIF $\alpha$ or $\beta$ chain expression in all tumour cells are clearly difficult to apply clinically. However, a recent study that used peptides that block the interaction between the HIF-1 $\alpha$ carboxyl-terminus and the transcriptional coactivator p300 [35] demonstrated reduction in growth and angiogenesis in tumours derived from breast and colon carcinoma cells. Equally, the recent identification of the key role of enzymatic modification of critical prolyl residues in HIF $\alpha$ chains provides hope that small molecule modulators of enzymatic activity may have therapeutic value, although it will probably be easier to identify enzyme inhibitors than potentiators.

It is important to sound two notes of caution, however. First, HIF downregulation will be detrimental in those circumstances in which the proapoptotic and antiproliferative effects predominate (although strategies to upregulate HIF, such as the use of peptides or enzyme inhibitors that block HIF degradation, might be applied to advantage in these circumstances). Second, the central role of the HIF system in the normal physiological adaptive responses to hypoxia 
suggests that manipulation of this system would have to be confined in some way to the tumour, if deleterious systemic side effects, such as anaemia, are to be avoided.

An alternative approach being investigated uses the activation of HIF in many tumours to direct therapeutic gene expression following introduction of gene therapy cassettes controlled by hypoxically regulated enhancers. Again, care will be needed to prevent unwanted therapeutic gene expression in areas of physiological hypoxia, such as the renal medulla.

\section{Conclusion}

The HIF system has a central role in physiological adaptation to hypoxia, and is frequently activated in tumours. Activation may occur simply as an expected consequence of microenvironmental hypoxia. However, a variety of genetic mechanisms that induce proliferation and are active in various tumours appear to sensitize the HIF system. It is therefore increasingly likely that there is a direct link between mechanisms that stimulate proliferation, thereby incurring an obligate energy cost, and this important system. In some tissues constitutive activation of the HIF system by inactivation of the VHL tumour suppressor protein is intimately linked to tumourigenesis.

The precise consequences of HIF activation vary between tumour types, with a balance between protumour and antitumour effects being manifest. In many tumours, however, it is likely that modulation of the HIF system or use of the upregulated HIF activity could be used to therapeutic advantage.

\section{Acknowledgement}

We acknowledge the contributions made to this field by many scientists whose work has not been directly cited due to lack of space. Work in our laboratory is principally funded by the Wellcome Trust and the Medical Research Council.

\section{References}

1. Maxwell PH, Pugh CW, Ratcliffe PJ: Inducible operation of the erythropoietin $3^{\prime}$ enhancer in multiple cell lines: evidence for a widespread oxygen sensing mechanism. Proc Natl Acad Sci USA 1993, 90:2423-2427.

2. Wang GL, Semenza GL: General involvement of hypoxiainducible factor 1 in transcriptional response to hypoxia. Proc Natl Acad Sci USA 1993, 90:4304-4308.

3. Wang GL, Jiang B-H, Rue EA, Semenza GL: Hypoxia-inducible factor 1 is a basic-helix-loop-helix-PAS heterodimer regulated by cellular $\mathrm{O}_{2}$ tension. Proc Natl Acad Sci USA 1995, 92: 5510-5514.

4. Ratcliffe PJ, Ebert BL, Firth JD, Gleadle JM, Maxwell PH, Nagao M, O'Rourke JF, Pugh CW, Wood SM: Oxygen regulated gene expression: erythropoietin as a model system. Kidney Int 1997, 51:514-526.

5. Ebert BL, Gleadle JM, O'Rourke JF, Bartlett SM, Poulton J ,Ratcliffe PJ: Isoenzyme specific regulation of genes involved in energy metabolism by hypoxia, cobalt and desferrioxamine: similarities with the regulation of erythropoietin. Biochem $J$ 1995, 313:809-814.

6. O'Rourke JF, Pugh CW, Bartlett SM, Ratcliffe PJ: Identification of hypoxically inducible mRNAs in Hela cells using differential display PCR. Eur J Biochem 1996, 241:403-410.
7. Wykoff CC, Pugh CW, Maxwell PH, Harris AL, Ratcliffe PJ: Identification of novel hypoxia-dependent and independent target genes of the von Hippel-Lindau (VHL) tumor suppressor by mRNA differential expression profiling. Oncogene 2000, 19: 6297-6305.

8. Arany Z, Huang LE, Eckner R, Bhattacharya S, Jiang C, Goldberg MA, Bunn HF, Livingston DM: An essential role for p300/CBP in the cellular response to hypoxia. Proc Natl Acad Sci USA 1996, 93:12969-12973.

9. Salceda S, Caro J: Hypoxia-inducible factor $1 \propto(\mathrm{HIF}-1 \propto)$ protein is rapidly degraded by the ubiquitin-proteasome system under normoxic conditions. J Biol Chem 1997, 272: 22642-22647.

10. Huang LE, Gu J, Schau M, Bunn HF: Regulation of hypoxiainducible factor $1 \mathrm{a}$ is mediated by an oxygen-dependent domain via the ubiquitin-proteasome pathway. Proc Natl Acad Sci USA 1998, 95:7987-7992.

11. Maxwell PH, Wiesener MS, Chang G-W, Clifford SC, Vaux EC, Cockman ME, Wykoff CC, Pugh CW, Maher ER, Ratcliffe PJ: The tumour suppressor protein VHL targets hypoxia-inducible factors for oxygen-dependent proteolysis. Nature 1999, 399: 271-275.

12. Cockman ME, Masson N, Mole DR, Jaakkola P, Chang GW, Clifford SC, Maher ER, Pugh CW, Ratcliffe PJ, Maxwell PH: Hypoxia inducible factor-alpha binding and ubiquitylation by the von Hippel-Lindau tumor suppressor protein. J Biol Chem 2000, 275:25733-25741.

13. Ivan $\mathrm{M}$, Kondo $\mathrm{K}$, Yang $\mathrm{H}$, Kim W, Valiando J, Ohh M, Salic A, Asara JM, Lane WS, Kaelin WG Jr: HIF $\alpha$ targeted for VHL-mediated destruction by proline hydroxylation: implications for $\mathrm{O}_{2}$ sensing. Science 2001, 292:464-468.

14. Jaakkola P, Mole DR, Tian Y-M, Wilson MI, Gielbert J, Gaskell SJ, von Kriegsheim K, Hebestreit HF, Mukherji M, Schofield CJ, Maxwell PH, Pugh CW, Ratcliffe PJ: Targeting of HIF- $\alpha$ to the von Hippel-Lindau ubiquitylation complex by $\mathrm{O}_{2}$-regulated prolyl hydroxylation. Science 2001, 292:468-472.

15. Maxwell PH, Dachs GU, Gleadle JM, Nicholls LG, Harris AL, Stratford IJ, Hankinson O, Pugh CW, Ratcliffe PJ: Hypoxia inducible factor-1 modulates gene expression in solid tumors and influences both angiogenesis and tumor growth. Proc Natl Acad Sci USA 1997, 94:8104-8109.

16. Dachs GU, Patterson AV, Firth JD, Ratcliffe PJ, Townsend KMS, Stratford IJ, Harris AL: Targeting gene expression to hypoxic tumour cells. Nat Med 1997, 3:515-520.

17. Zhong $\mathrm{H}$, De Marzo AM, Laughner E, Lim M, Hilton DA, Zagzag D, Buechler P, Isaacs WB, Semenza GL, Simons JW: Overexpression of hypoxia-inducible factor $1 \alpha$ in common human cancers and their metastases. Cancer Res 1999, 59:58305835.

18. Talks K, Turley H, Gatter KC, Maxwell PH, Pugh CW, Ratcliffe PJ, Harris AL: The expression and distribution of the hypoxiainducible factors HIF-1alpha and HIF-2alpha in normal human tissues, cancers, and tumor-associated macrophages. $A m \mathrm{~J}$ Pathol 2000, 157:411-421.

19. Richard DE, Berra E, Pouyssegur J: Non-hypoxic pathway mediates the induction of hypoxia inducible factor 1 alpha (HIF-1 $\alpha$ ) in vascular smooth muscle cells. J Biol Chem 2000, 275: 26765-26771.

20. Semenza GL: Hypoxia, clonal selection, and the role of HIF-1 in tumor progression. Crit Rev Biochem Mol Biol 2000, 35:71103.

21. Jiang BH, Agani F, Passaniti A, Semenza GL: V-SRC induces expression of hypoxia-inducible factor 1 (HIF-1) and transcription of genes encoding vascular endothelial growth factor and enolase 1: involvement of HIF-1 in tumor progression. Cancer Res 1997, 57:5328-5335.

22. Zundel W, Schindler C, Haas-Kogan D, Koong A, Kaper F, Chen E, Gottschalk AR, Ryan HE, Johnson RS, Jefferson AB, Stokoe D, Giaccia AJ: Loss of PTEN facilitates HIF-1-mediated gene expression. Genes Dev 2000, 14:391-396.

23. Zhong $H$, Chiles $K$, Feldser D, Laughner $E$, Hanrahan $C$, Georgescu M-M, Simons JW, Semenza GL: Modulation of hypoxia-inducible factor la expression by the epidermal growth factor/phosphatidylinositol 3-kinase/PTEN/AKT/ FRAP pathway in human prostate cancer cells: implications for tumor angiogenesis and therapeutics. Cancer Res 2000, 60:1541-1545. 
24. Mazure NM, Chen EY, Laderoute KR, Giaccia AJ: Induction of a vascular endothelial growth factor by hypoxia is modulated by a phosphatidylinositol 3-kinase/Akt signaling pathway in Haras-transformed cells through a hypoxia inducible factor-1 transcriptional element. Blood 1997, 90:3322-3331.

25. Chen C, Pore N, Behrooz A, Ismail-Beigi F, Maity A: Regulation of glut1 mRNA by hypoxia inducible factor-1: interaction between H-ras and hypoxia. J Biol Chem 2001, 276:95199525.

26. Richard DE, Berra E, Gothie E, Roux D, Pouysségur J: p42/p44 mitogen-activated protein kinases phosphorylate hypoxiainducible factor $1 \alpha$ (HIF-1 $\alpha)$ and enhance the transcriptional activity of HIF-1. J Biol Chem 1999, 274:32631-32637.

27. Ravi $R$, Mookeriee $B$, Bhujwalla $Z M$, Sutter $C H$, Artemov $D$, Zeng Q, Dillehay LE, Madan A, Semenza GL, Bedi A: Regulation of tumor angiogenesis by p53-induced degradation of hypoxiainducible factor $1 \alpha$. Genes Dev 2000, 14:34-44.

28. Shim H, Dolde C, Lewis BC, Wu C-S, Dang G, Jungmann RA, Dalla-Favera $\mathrm{R}$, Dang $\mathrm{CV}$ : c-Myc transactivation of $L D H-A$ : implications for tumor metabolism and growth. Proc Natl Acad Sci USA 1997, 94:6658-6663.

29. Ryan HE, Lo J, Johnson RS: HIF-1a is required for solid tumor formation and embryonic vascularization. $E M B O J 1998,17$ : 3005-3015.

30. Carmeliet $P$, Dor $Y$, Herbert JM, Fukumura $D$, Brusselmans $K$ Dewerchin M, Neeman M, Bono F, Abramovitch R, Maxwell $P$, Koch CJ, Ratcliffe P, Moons L, Jain RK, Collen D, Keshet E: Role of HIF-1alpha in hypoxia-mediated apoptosis, cell proliferation and tumour angiogenesis. Nature 1998, 394:485-490.

31. Ryan HE, Poloni M, McNulty W, Elson D, Gassmann M, Arbeit JM, Johnson RS: Hypoxia-inducible factor-l $\alpha$ is a positive factor in solid tumor growth. Cancer Res 2000, 60:4010-4015.

32. Hockel M, Knoop C, Schlenger K, Vorndran B, Baussmann E, Mitze M, Knapstein PG, Vaupel P: Intratumoral pO2 predicts survival in advanced cancer of the uterine cervix. Radiother Oncol 1993, 26:45-50.

33. Birner P, Schindl M, Obermair A, Plank C, Breitenecker G, Oberhuber G: Overexpression of hypoxia-inducible factor l $\alpha$ is a marker for an unfavorable prognosis in early-stage invasive cervical cancer. Cancer Res 2000, 60:4693-4696.

34. Volm M, Koomagi R: Hypoxia-inducible factor (HIF-1) and its relationship to apoptosis and proliferation in lung cancer. Anticancer Res 2000, 20:1527-1533.

35. Kung AL, Wang S, Klco JM, Kaelin WG, Livingston DM: Suppression of tumor growth through disruption of hypoxia-inducible transcription. Nat Med 2000, 6:1335-1340. 